\title{
GROWTH AND CHARACTERIZATION OF N-METHYLUREA OXALIC (NMUO) ACID SINGLE CRYSTAL
}

\author{
K. Senthil ${ }^{1}$, K. Elangovan ${ }^{1, *}$, A. Senthil ${ }^{1}$ and G. Vinitha ${ }^{2}$ \\ ${ }^{1}$ Department of Physics, SRM Institute of Science and Technology, \\ Ramapuram Campus, Chennai - 600 089, India. \\ ${ }^{2}$ Department of Physics, School of Advanced Sciences, \\ VIT Chennai, 600127 Tamil Nadu, India. \\ *E-mail: elangovan2002@gmail.com
}

\begin{abstract}
N-Methylurea oxalic (NMUO) acid organic crystals were grown by solution method with slow evaporation solution technique (SEST) in aqueous solution. Using single crystal XRD (SCXRD) analysis, the structure of the crystal was determined. The powder X-ray diffraction (PXRD) study reveals that the crystallinity of the specimen. The functional groups of the title molecule were determined from FTIR and FT-Raman analyses. Optical transmittance of the crystal was studied using UV-Visible spectroscopy. The hardness of the grown crystal was found by Vickers microhardness test. The dielectric behavior of the crystal was determined at $30^{\circ} \mathrm{C}$ temperature. The thermal stability of the crystal was studied by thermogravimetric analysis (TG/GTG) and differential scanning calorimetry (DSC). Zscan characterization was carried out to investigate the third-order nonlinear optical properties of the crystal.

Keywords: Single XRD, FTIR Spectrum, Vickers Microhardness, UV-Visible Spectral Analysis, Dielectric Analysis, Thermal Analysis.
\end{abstract}

(C) RASĀYAN. All rights reserved

\section{INTRODUCTION}

For the applications of telecommunication, optical computing, frequency conversion, optical information processing and high optical data storage the material should exhibit large optical nonlinearity ${ }^{1-3}$. Generally, the materials of the good optical property with less dislocation density and large charge transfer are favorable for optical applications. In recent years, due to the above features, the organic crystals are highly applicable for the field of frequency doubling, optoelectronic and telecommunication ${ }^{4-}$ ${ }^{8}$. N-methyl urea (NMU) is one of the promising organic nonlinear optical materials ${ }^{9,}{ }^{10}$. The literature reports say that the enhanced properties of the co-crystals and salts are observed from NMU ${ }^{11-14}$. To form convenient hosts for the study of carboxyl anion radicals and their changes, the simplest of the dicarboxylic acid of oxalates was used. Particularly, the addition of urea with oxalic acid makes attractive features. According to Harkema et al. ${ }^{15}$ reported that the crystal structure of N-methyl urea-oxalic acid and which is crystallized in the monoclinic system with the space group $\mathrm{P} 2{ }_{1} / \mathrm{c}$. In this manuscript, we have grown N-methylurea-oxalic acid (NMUO) crystal and have been reported it's physical by the characterizations of single crystal XRD, FTIR, FT-Raman, UV-Visible transmittance, dielectric, thermal and Z-scan study.

\section{Synthesis and Crystal Growth}

\section{EXPERIMENTAL}

The N-methyl urea oxalic acid (NMUO) was synthesized by slow evaporation of an aqueous solution with 2:1 ratio ${ }^{15}$ of $\mathrm{N}$-methyl urea and oxalic acid. $\mathrm{N}$-methyl urea and oxalic acid were dissolved simultaneously drop by drop in double distilled water using a magnetic stirrer. The prepared solution was allowed to evaporate at room temperature, which yields the salt of NMUO. The purity of the synthesized material was further improved by the process of re-crystallization. A saturated solution of NMUO was prepared using the recrystallized materials and the solution was taken in a beaker. The solution was Rasayan J. Chem., 12(3), 1262-1268(2019)

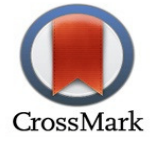


allowed to evaporate by keeping the temperature at $35^{\circ} \mathrm{C}$. The supersaturated solution was kept the undisturbed atmosphere at $35^{\circ} \mathrm{C}$ temperature. Finally, the optically good quality crystals were harvested. The crystals were grown in a period of 45 days. The grown NMUO single crystal is shown in Fig.-1.

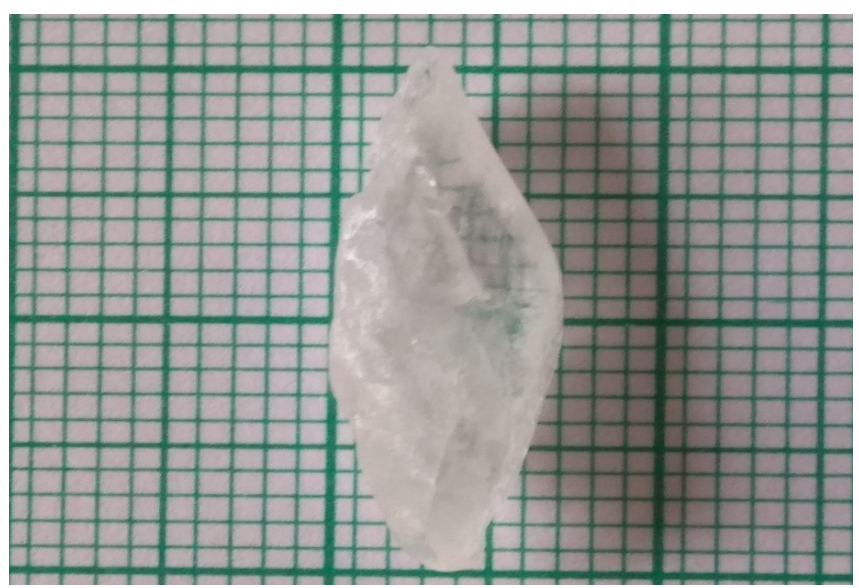

\section{Characterization Details}

Fig.-1: Photograph of grown NMUO single crystal

The NMUO crystal was grown and subjected to various characterizations. Single crystal XRD was carried out using Bruker-Nonius MACH3/CAD4 X-ray diffractometer. Using the X'pert PRO powder Xray diffractometer using $\mathrm{Cu}-\mathrm{Ka}$ radiation of wavelength $\lambda=1.5406 \AA$ the powder XRD was carried out. The optical transmission spectrum of NMUO crystal was recorded in the range 200-1100 nm using Lambda 35 spectrophotometer. A dielectric study was carried out as a function of frequency for room temperatures using an LCR meter. Thermogravimetric (TG/DTG) and differential scanning calorimetry (DSC) recorded using Perkin Elmer Diamond TG and DSC instrument. Z-scan measurement was carried out using $532 \mathrm{~nm}$ laser wavelength to get third-order nonlinear optical parameters.

\section{X-Ray Diffraction Analysis}

\section{RESULTS AND DISCUSSION}

The structure of the grown NMUO single crystal was analyzed by SCXRD analysis. From the result, it was revealed that the grown crystal belongs to monoclinic structure and unit cell parameter values $\mathrm{a}=$ $5.14 \AA, b=10.53 \AA$ and $c=10.21 \AA$, are well agree with reported literature ${ }^{15}$. NMUO crystal was finely powdered and subjected to powder XRD analysis with an X'pert PRO powder X-ray Diffractometer. The PXRD data were recorded for the angle range between 5 to $50^{\circ}$. The PXRD pattern of NMUO is shown in Fig. 2. Sharpness in the peak pattern in PXRD revealed that the crystallinity of the material.

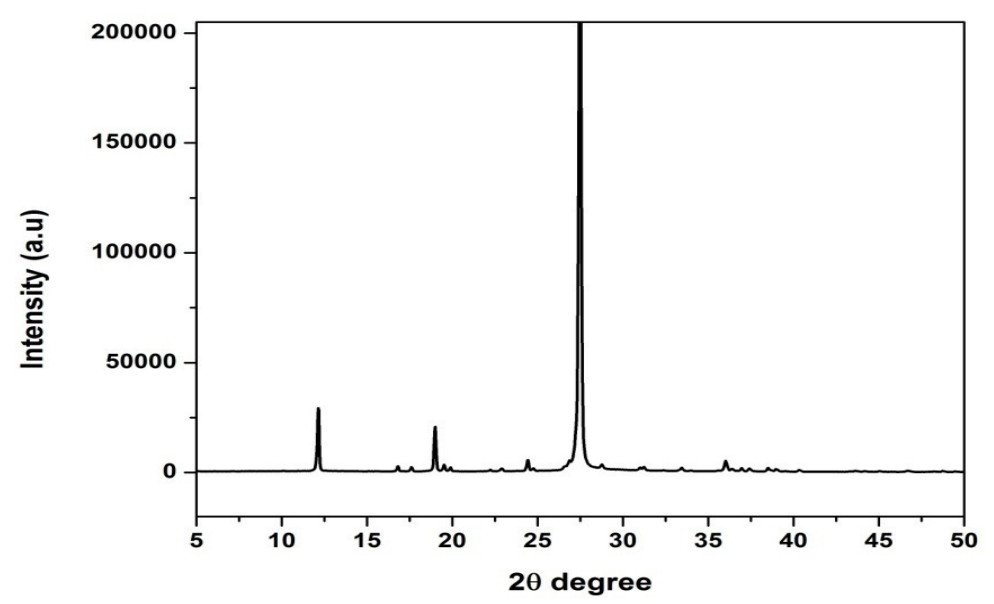

Fig.-2: Powder XRD Pattern of NMUO 


\section{FTIR and FT-Raman Spectral Analysis}

Fourier transform infrared (FTIR) and FT-Raman spectrum was recorded for NMUO material at $30{ }^{\circ} \mathrm{C}$ temperature and it is shown in Fig.-3 and 4.

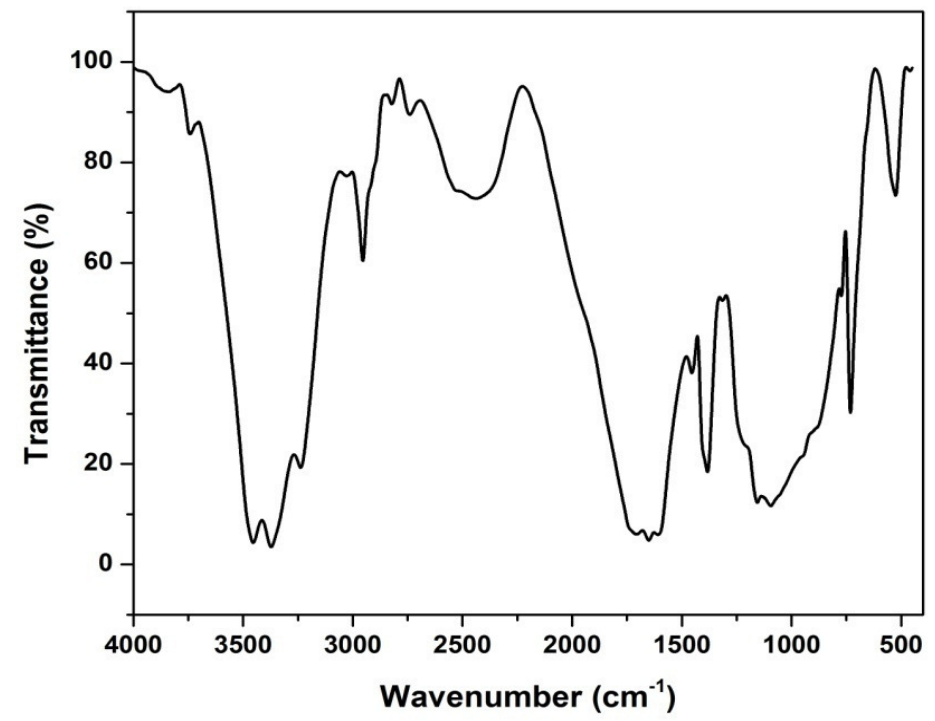

Fig.-3: FTIR Spectrum of NMUO

From the figures, the asymmetric and symmetric vibrations of the methyl group are observed at 3029, 2955 and 2953, $2827 \mathrm{~cm}^{-1}$ in FTIR and FT-Raman respectively ${ }^{16-17}$. The infrared absorption wavenumber at 1718, 1714, 1655, 1751 and $1740,1647 \mathrm{~cm}^{-1}$ in FTIR and FT-Raman respectively due to C=O stretching vibrations of oxalic acid. ${ }^{18-20}$. Primary amine of $\mathrm{N}-\mathrm{H}$ stretching vibrations of $\mathrm{N}$-methyl urea was observed at 3454,3371 and $3369 \mathrm{~cm}^{-1}$ in FTIR and FT-Raman respectively ${ }^{21-23}$. Thus, FTIR spectra confirmed the presence of various representative functional groups in NMUO crystal.

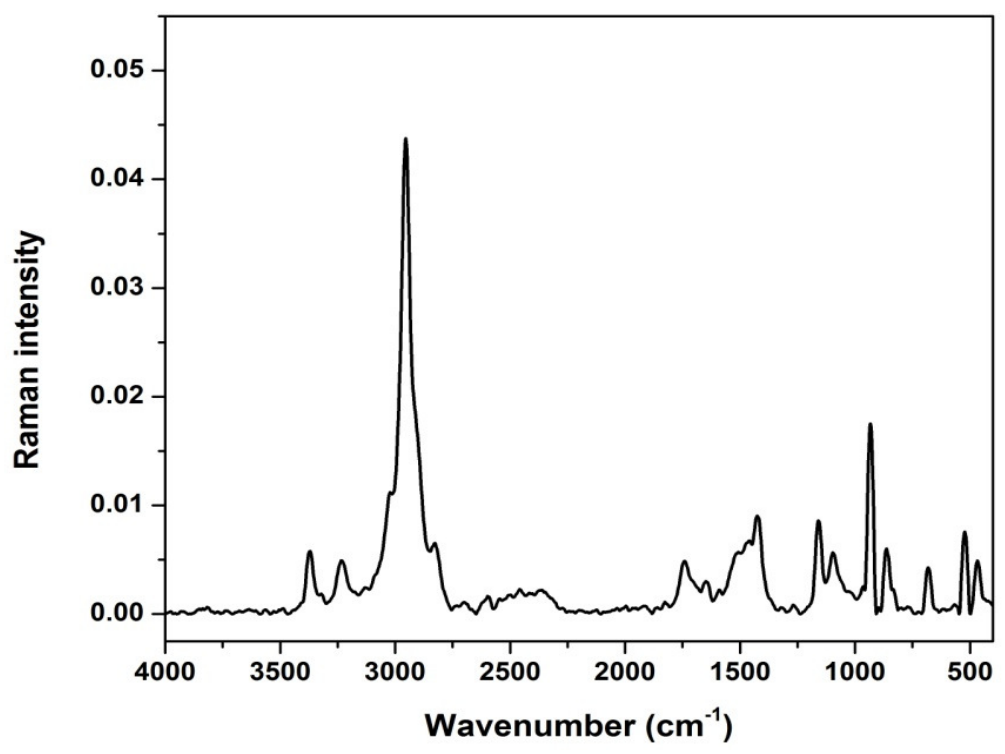

UV-Visible Spectral Analysis

Fig.-4: FT-Raman Spectrum of NMUO

To find the optical properties of the crystal, the optical transmittance of the crystal was carried out. The obtained UV-Visible spectrum of NMUO crystal is shown in Fig.5. It has considerably high transparency in the entire visible and there is no absorption was observed in the entire visible region. The fundamental absorption edge was observed at $296 \mathrm{~nm}$. From the electronic band structure, electrical properties, the electronic transition was obtained for the material ${ }^{24}$. There is no absorption in the entire visible region of 
the spectrum as shown in Fig. 4. Hence, the wide transmittance window of the crystal in the entire visible region makes that the title crystal can be applicable for various optical applications.

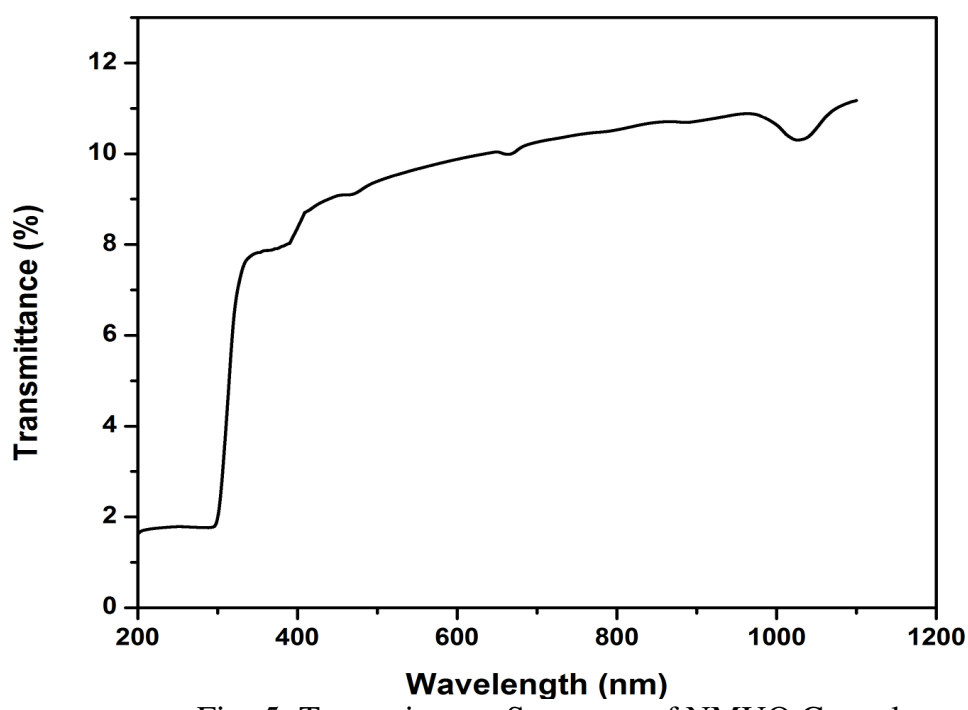

\section{Dielectric Studies}

Fig.-5: Transmittance Spectrum of NMUO Crystal

A study of dielectric properties of organic optical material is important for the applications of fast switching times in electro-optic applications, the dielectric study was important in the organic materials ${ }^{25}$. Cut and polished samples were used for this characterization. The good quality silver paste was coated on two opposite surface of the crystal to obtain good contact in order to observe the dielectric result. The dielectric loss variations with frequency are shown in Fig.-6.

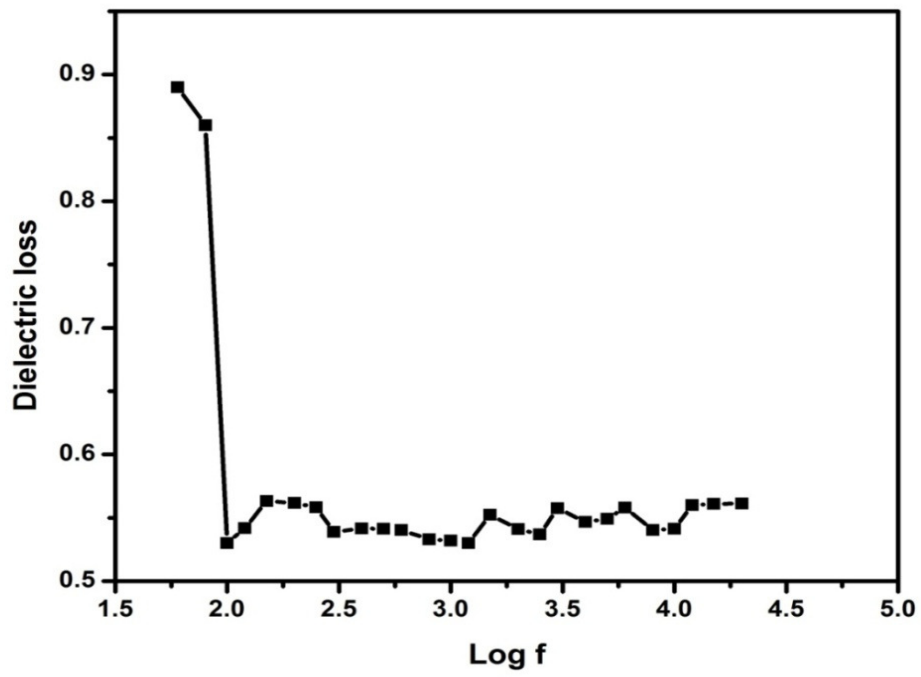

Fig.-6: Dielectric Loss of NMUO Crystal

The measurement was taken from the frequency range $5 \mathrm{~Hz}-20 \mathrm{MHz}$ to study the dielectric loss of the crystal. The good optical quality with smaller defects in the material was revealed by the results of the low value of the dielectric loss at maximum frequencies, this behavior plays important role in the fabrication of NLO optical devices ${ }^{26}$.

\section{Thermal Analysis}

From the TG/DTG measurement, the thermal stability and the melting point of the material were obtained and the results as shown in Fig.-7. The temperature range was adopted to measure the thermal analysis of the material $25-370{ }^{\circ} \mathrm{C}$. 


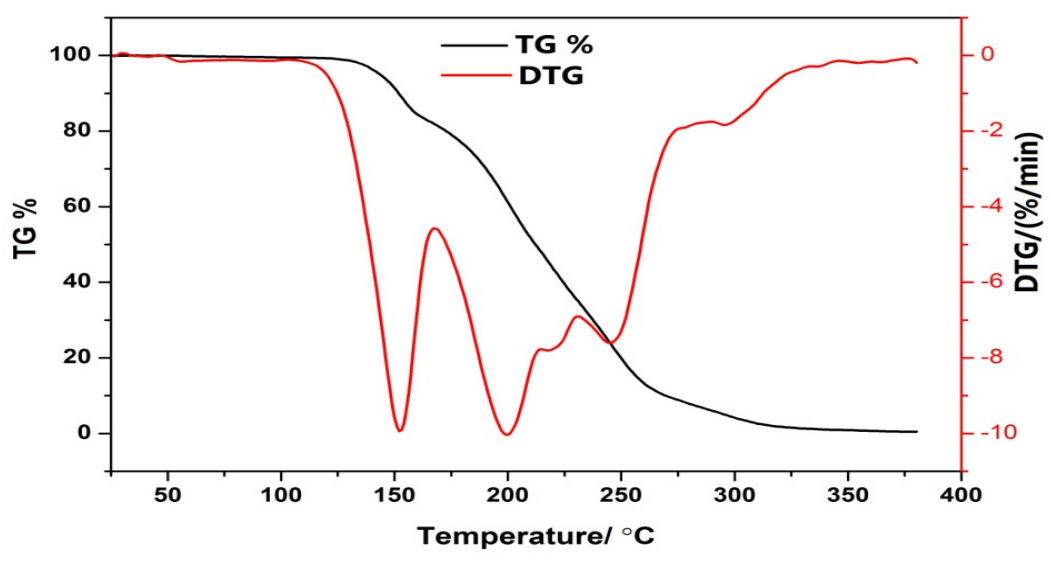

Fig.-7: TG/DTG Spectrum of NMUO Crystal

From the figure, the four stages of weight loss were observed for the material. The first step decomposition was observed from the temperature range $99{ }^{\circ} \mathrm{C}$ to $162{ }^{\circ} \mathrm{C}$ with a weight loss of $17.89 \%$, the first weight loss is attributed to the decomposition of water molecule $(17 \%)$ in the range between 99 ${ }^{\circ} \mathrm{C}$ and $146^{\circ} \mathrm{C}$, the second stage of weight loss $(45.98 \%)$ occurs in the temperature range between $162{ }^{\circ} \mathrm{C}$ and $230{ }^{\circ} \mathrm{C}$, the oxalic acid into carbon dioxide $\left(\mathrm{CO}_{2}\right)$ decomposition was takes place and the corresponding endothermic peak was observed at $202{ }^{\circ} \mathrm{C}$. in the material and corresponding small endothermic peak absorbed around $202{ }^{\circ} \mathrm{C}$. Third stage weight loss from 230.4 to $280.7^{\circ} \mathrm{C}$ with a weight loss of $27.95 \%$ and the final weight loss occurs from 280.7 to $340{ }^{\circ} \mathrm{C}$ with weight loss of $6.78 \%$. Finally, the residue was observed as $0.44 \%$ at $400{ }^{\circ} \mathrm{C}$. The DSC curve of NMUO was recorded result as shown in Fig.-8.

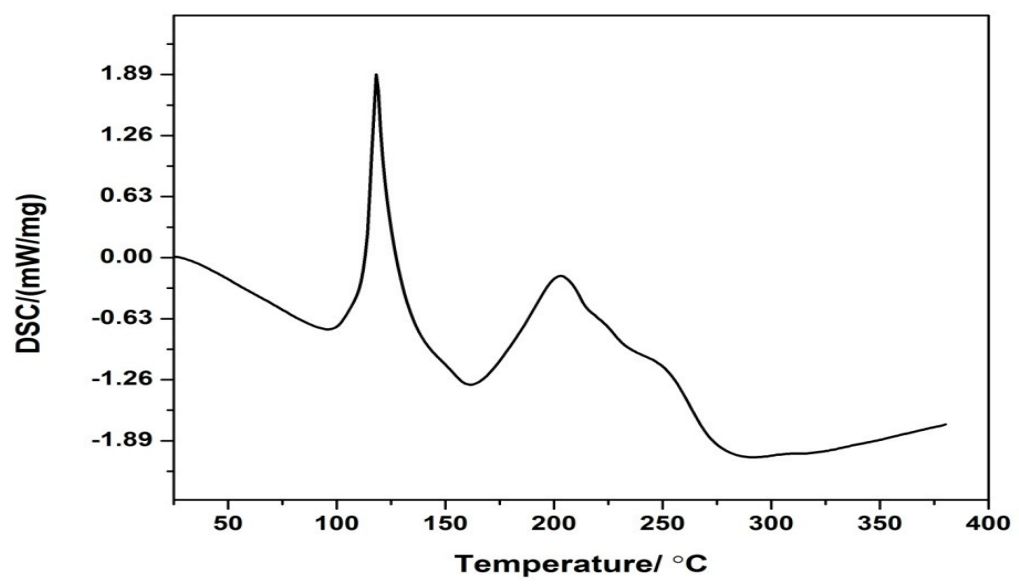

Fig.-8: DSC Spectrum of NMUO Crystal

From the DSC curve, there is no structural and phase transformation was observed up to $120{ }^{\circ} \mathrm{C}$. A sharp endothermic peak at 120 in DSC is due to the sample's melting process, the higher melting point and the sharpness of DSC melting peak reveal that NMUO has purity and good crystallinity.

\section{Z-Scan Study}

For studying the optical nonlinearities of the materials such as semiconductors, organic materials and nanoparticles, the Z-scan technique was extensively used. To measure the nonlinear absorption coefficient $(\beta)$ and the nonlinear index of refraction $\left(\mathrm{n}_{2}\right)$ of the material, it was an accurate method. Single beam Zscan technique is one of the widely employed techniques to In the determination of nonlinear absorption and refraction, the Z-scan techniques with a single beam was widely used method ${ }^{27}$. The closed and open aperture curves of NMUO crystal are shown in Fig.-9 and 10. 
And the real and imaginary parts of the third-order nonlinear optical susceptibility $\chi^{3}$ are calculated by the relations,

$\mathrm{R}_{\mathrm{e}} \chi^{(3)}(\mathrm{esu})=10^{-4} \varepsilon_{0} \mathrm{c}^{2} \mathrm{n}_{0}{ }^{2} \mathrm{n}_{2} / \pi\left(\mathrm{cm}^{2} \mathrm{~W}^{-1}\right)$

$\mathrm{I}_{\mathrm{m}} \chi^{(3)} \quad(\mathrm{esu})=10^{-2} \varepsilon_{0} \mathrm{c}^{2} \mathrm{n}_{0}{ }^{2} \lambda \beta / 4 \pi\left(\mathrm{cm} \mathrm{W}^{-1}\right)$

$\chi^{(3)}=\sqrt{ }\left(\mathrm{R}_{\mathrm{e}} \chi^{(3)}\right)^{2}+\left(\mathrm{I}_{\mathrm{m}} \chi^{(3)}\right)^{2}$

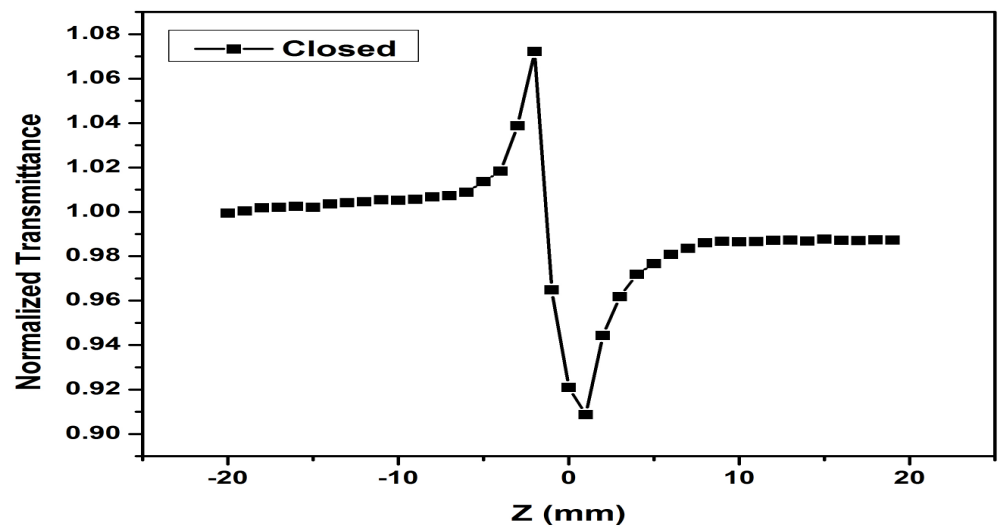

Fig.-9: Closed Aperture Curve of NMUO Crystal

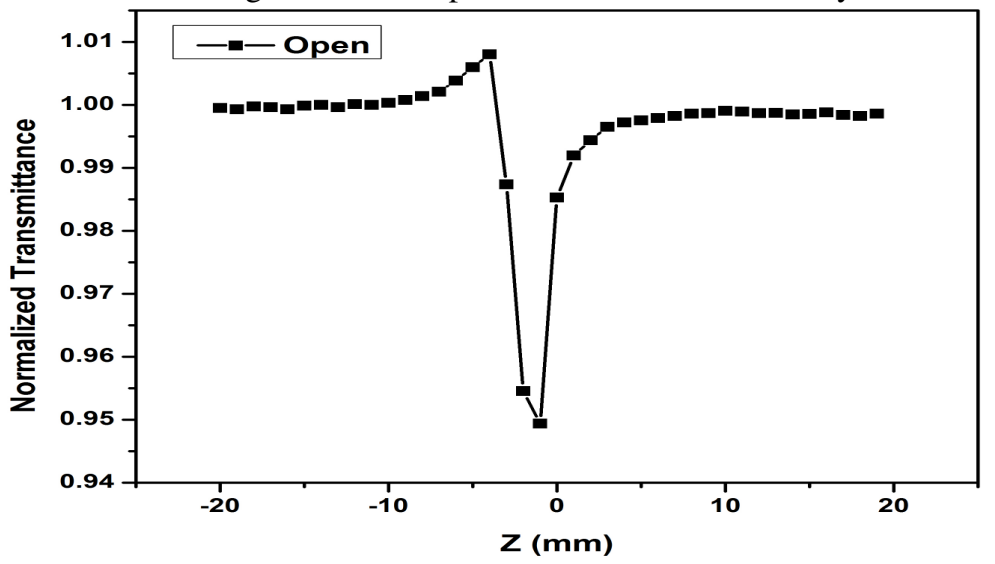

Fig.-10: Open Aperture Curve of NMUO Crystal

The calculated third-order NLO parameters are given in the Table-1.

Table-1: Calculated Third-Order Nonlinear Optical Parameter of NMUO Crystal

\begin{tabular}{c|c|c|c|c|c}
\hline $\begin{array}{c}\mathrm{n}_{2} \\
\left(\mathrm{~cm}^{2} / \mathrm{W}\right)\end{array}$ & $\alpha$ & $\begin{array}{c}\beta \\
(\mathrm{cm} / \mathrm{W})\end{array}$ & $\begin{array}{c}\operatorname{Re} \chi^{(3)} \\
(\mathrm{esu})\end{array}$ & $\begin{array}{c}\operatorname{Im} \chi^{(3)} \\
(\mathrm{esu})\end{array}$ & $\begin{array}{c}\chi^{(3)} \\
(\mathrm{esu})\end{array}$ \\
\hline $5.43 \times 10^{-09}$ & 391.98 & 0.000164 & $7.94 \times 10^{-7}$ & $1.02 \times^{-5}$ & $1.02 \times^{-5}$ \\
\hline
\end{tabular}

CONCLUSION

Good quality of N-methylurea-oxalic acid (NMUO) single crystal was grown in water solvent by SEST method. The SCXRD measurement confirms that the crystal crystallizes in monoclinic $\left(\mathrm{P} 2_{1} / \mathrm{c}\right)$ system. The functional groups of the title compound were confirmed by FT-IR and Raman analyses. Optical transmission study showed that NMUO crystal was optically good transparent with cut off wavelength at $296 \mathrm{~nm}$ and the band gap was found to be $\mathrm{E}_{\mathrm{g}}=4.1 \mathrm{eV}$. The dielectric loss of the crystal was determined at $30{ }^{\circ} \mathrm{C}$ temperature and the results show that the crystal has normal dielectric behavior. The thermal stability of the material was studied as $120^{\circ} \mathrm{C}$ by TG/DTG and DSC analysis. Form the Z-scan study third-order nonlinear optical susceptibility was calculated to be $1.02 x^{-5}$ esu. The results observed in NMUO suggested that the title crystal is suitable for electro-optic and NLO applications. 
RASĀYAN J. Chem.

Vol. 12 | No. 3 |1262 - 1268| July - September | 2019

\section{REFERENCES}

1. N. Senthilvelan, G. Rajarajan, A.Jegatheesan, S. Sivakumar and J. Elanchezhiyan, Rasayan J. Chem., 10 (1), 218(2017), DOI:10.7324/RJC.2017.1011565

2. Yuan D R, Xu D, Zhang N, Liu MG, Jiang MH, Chin. Phys. Lett., 13, 841(1996), DOI: 10.1088/0256-307X/13/11/011.

3. M. Iwai, T. Kobayashi, H. Furya, Y. Mori, T. Sasaki, Jpn. J. Appl. Phys., 36, L276 (1997), DOI: 10.1143/JJAP.36.L276.

4. N. Ramamurthy, S. Dhanuskodi, M.V. Manjusha, J. Philip, Opt. Mater., 33, 607(2011), DOI: 10.1016/j.optmat.2010.11.010.

5. G. Venkatesan, G. Anandha Babu, P. Ramasamy, A. Chandramohan, J. Mol. Struct. , 1033, 121 (2013), DOI: $10.1016 /$ j.molstruc.2012.08.019.

6. R.W. Munn, C.N. Ironside, Principles and Applications of Nonlinear Optical Materials, Chapman \& Hall, London, (1993).

7. M. Jose, R. Uthrakumar, A. Jeya Rajendran, S. Jerome Das, Spectrochim, Acta A: Mol. Biomol. Spectrocopy, 86, 495 (2012), DOI: 10.1016/j.saa.2011.11.002.

8. S. Lin, L. Li, J. Chen, Y. Chen, J. Cryst. Growth, 249, 341 (2003), DOI:10.1016/S00220248(02)02106-1.

9. L. Zeng, M. Zha, L. Zanotti, C. Razzetti and C. Paorici, J. Crystal Growth, 147, 74(1995), DOI: 10.1016/0022-0248(94)00651-2.

10. R.I. Ristic, B.Yu. Sherkunov and J.N. Sherwood, J. Crystal Growth, 167, 693(1996), DOI: 10.1016/0022-0248(96)00281-3

11. J.N. Sherwood and G.S. Simpson, J. Crystal Growth, 167, 709 (1996), DOI: 10.1016/00220248(96)00283-7

12. A. O. Jones, C. K. Leech, G. J. McIntyre, C. C. Wilson and L. H. Thomas, Cryst. Eng. Comm. , 16 (35), 8177(2014), DOI: 10.1039/C4CE00587B.

13. J. H. Bryden, Acta Crystallogr., 10(11), 714(1957), DOI: 10.1107/S0365110X57002510.

14. A. J. Rybarczyk-Pirek, Struct. Chem., 23(6), 1739(2012), DOI:10.1007/s11224-012-9980-7.

15. S. Harkema, J. H. M. Ter Brake and H. J. G. Meutstege, Acta Crystallogr., Sect. B: Struct. Crystallogr. Cryst. Chem., 35(9), 2087(1979), DOI: 10.1107/S0567740879008517.

16. G. Varsanyi, Vibrational Spectra of Benzene Derivatives, Academic Press, New York, (1969).

17. M. Silverstein, G. Clayton Basseler, C. Morill, Spectrometric Identification of Organic Compounds, Wiley, New York, (1981).

18. M. Silverstein, G. Clayton Basseler, C. Morill, Spectrometric Identification of Organic Compounds, Wiley, New York, (1981).

19. Mehmet Karabacak, J. Mol. Struct., 919, 215 (2009), DOI: 10.1016/j.molstruc.2008.09.012.

20. D.L. Vein, N.B. Colthup, W.G. Fateley, J.G. Grasselli, The Handbook of Infrared and Raman Characteristic Frequencies of Organic Molecules, Academic Press, San Diego, (1991).

21. S. Ramalingam, S. Periandy, B. Narayanan, S. Mohan, Spectrochim. Acta A, 76, 84(2010), DOI:1016/j.saa.2010.02.050.

22. Y. Wang, S. Saebo, C.U. Pittman, J. Mol. Struct. (Theochem), 281, 91(1993), DOI: 10.1016/01661280(93)87064-K

23. K. Nivetha, S. Kalainathan, M. Yamada, Y. Kondo, F. Hamada, RSC Adv., 6, 35977(2016), DOI:10.1039/C6RA02544G.

24. K. Senthil, S. Kalainathan, A. Ruban Kumar, J. Therm. Anal. Calorim., 118, 323(2014), DOI: $10.1007 / \mathrm{s} 1097$.

25. C. Balarew, R. Duhlev, J. Solid Sate Chem., 55, 1(1984), DOI:10.1016/0022-4596(84)90240-8

26. E.W. Van Stryland, M. Sheik-Bahae, M.G. Kuzyk, C.W. Dirk (Eds.), CharacterizationTechniques and Tabulations for Organic Nonlinear Materials, Vol. 655-692, Marcel Dekker, Inc., (1998).

[RJC- 5174/2019] 